\title{
Apolipoprotein L1, income and early kidney damage
}

\author{
Ruth Tamrat ${ }^{1}$, Carmen A Peralta ${ }^{2,3}$, Salman M Tajuddin ${ }^{4}$, Michele K Evans ${ }^{4}$, Alan B Zonderman ${ }^{4}$ \\ and Deidra C Crews ${ }^{1,5,6,7^{*}}$
}

\begin{abstract}
Background: The degree to which genetic or environmental factors are associated with early kidney damage among African Americans (AAs) is unknown.

Methods: Among 462 AAs in the Healthy Aging in Neighborhoods of Diversity across the Life Span (HANDLS) study, we examined the cross-sectional association between apolipoprotein L1 (APOL1) risk variants and income with: 1) mildly reduced eGFR ( $<75 \mathrm{~mL} / \mathrm{min} / 1.73 \mathrm{~m}^{2}$, creatinine-cystatin C equation) and 2) elevated urine albumin-to-creatinine ratio (ACR) ( $\geq 17$ in men and $\geq 25 \mathrm{mg} / \mathrm{g}$ in women). High risk APOL1 status was defined by 2 copies of high-risk variants; low risk if 0 or 1 copy. Income groups were dichotomized as $<\$ 14,000 /$ year (lowest income group) or $\geq \$ 14,000 /$ year. Logistic regression models were adjusted for age, sex, and \% European ancestry.

Results: Overall, participants' mean age was 47 years and 16\% $(n=73)$ had high risk APOL 1 status. Mean eGFR was $99 \mathrm{~mL} / \mathrm{min} / 1.73 \mathrm{~m}^{2}$. Mildly reduced eGFR was prevalent among 11\% $(n=51)$. The lowest income group had higher adjusted odds (aOR) of mildly reduced eGFR than the higher income group (aOR 1.8, 95\% Cl 1.2-2.7). High-risk APOL1 was not significantly associated with reduced eGFR (aOR 1.5, 95\% Cl 0.9-2.5). Among 301 participants with ACR data, 7\% $(n=21)$ had elevated ACR. Compared to low-risk, persons with high-risk APOL 1 had higher odds of elevated ACR (aOR 3.8, $95 \% \mathrm{Cl}$ 2.0-7.3). Income was not significantly associated with elevated ACR (aOR 1.8, 95\% Cl 0.7-4.5). There were no significant interactions between $A P O L 1$ and income.
\end{abstract}

Conclusions: Both genetic and socioeconomic factors may be important determinants of early kidney damage among AAs.

Keywords: APOL1, Chronic kidney disease, Socioeconomic status, African American, Renal, Albuminuria

\section{Background}

Apolipoprotein L1 (APOL1) belongs to a family of genes which encode for lipoproteins that are likely involved in the transport and metabolism of lipids. Unlike others in this gene family, $A P O L 1$ possesses a signal sequence that allows for it to be exported out of the cell. Once extracellular, APOL1 associates with HDL particles and may play a role in programmed cell death $[1,2]$. While they confer protection against the parasite Trypanosoma brucei, genetic variants in the APOL1 region of chromosome 22 have been identified as major determinants of

\footnotetext{
* Correspondence: dcrews1@jhmi.edu

'Department of Medicine, Johns Hopkins University School of Medicine, Baltimore, MD, USA

${ }^{5}$ Welch Center for Prevention, Epidemiology and Clinical Research, Johns Hopkins Medical Institutions, Baltimore, MD, USA

Full list of author information is available at the end of the article
}

chronic kidney disease (CKD) in African Americans. The two most common high-risk variants of APOL1, G1 and G2, are only seen among individuals of West African descent, with approximately $12 \%$ of African Americans having two high-risk variants. In contrast, these high-risk variants are virtually nonexistent among Asians, Europeans, and Hispanics [3,4]. Multiple studies have now shown that, compared to those with zero or one high-risk variant, the presence of two high-risk variants is associated with advanced kidney disease in the setting of focal segmental glomerulosclerosis [3], hypertensionattributed nephropathy [5] and HIV-associated nephropathy [6]. High-risk APOL1 is also associated with progression of established CKD, independent of diabetes status [7]. Less is known about the relation of APOL1 and early kidney damage. Some studies have shown associations 
between having two 2 high-risk APOL1 variants and prevalent high ACR [8] and very high ACR [9] among populations with largely preserved eGFR.

However, importantly, not all African Americans with two high-risk variants develop incident [10] or progressive CKD [7], suggesting that a "second hit" may be required. This second hit may be environmental, including infectious factors (as in the case of HIV associated nephropathy), as well as factors related to socioeconomic status (SES) or comorbid disease burden. Multiple studies have found that adjustment for SES attenuates observed disparities in kidney-related outcomes between African Americans and whites, suggesting that factors related to low SES contribute to the excess risk of advanced CKD and ESRD seen among African Americans $[11,12]$. Some studies have found that low SES correlates more strongly with CKD/ESRD among African Americans than whites, further supporting the notion of environmental contributions to racial disparities [13-15]. There are many possible mechanisms through which SES could contribute to these disparities, and several models have been proposed $[11,16]$. For example, limited availability of healthful foods in the neighborhoods of many low SES African Americans could lead to poor dietary patterns $[17,18]$, which could ultimately affect CKD risk- particularly given the growing body of evidence supporting that dietary patterns rich in fruits and vegetables could be kidney protective [19-21].

Despite recent advances in understanding genetic contributions to racial disparities in CKD, questions still remain, including the relation of genetic factors to the variation in GFR among populations largely free of established CKD [8]. Furthermore, the possible role of gene-environment interactions in determining early kidney disease among African Americans has not been well-explored. Therefore, the objective of this study was to evaluate whether genetic factors, environmental factors (SES), or their interaction are associated with markers of renal dysfunction among persons without established CKD in an urban population of predominantly low income African Americans.

\section{Methods \\ Healthy Aging in Neighborhoods of Diversity across the Life Span (HANDLS): design and population}

We examined cross-sectional data from the National Institute on Aging (NIA), HANDLS study. HANDLS is a community-based cohort study examining the influences of race and SES on the development of health disparities among minority and lower SES subpopulations. This cohort, recruited between 2004 and 2008, is comprised of self-identified African Americans and whites 30-64 years of age at baseline, from 13 Baltimore, MD neighborhoods selected to reflect socioeconomic and racial diversity. Each participant provided informed consent, and the National
Institute of Environmental Health Sciences Institutional Review Board approved the study protocol [22].

The total HANDLS population is 3,720. For the purposes of our study, we restricted our analysis to AfricanAmerican participants $(\mathrm{N}=2200)$ who were genotyped for APOL1 $(\mathrm{N}=1024)$, underwent baseline serum cystatin $\mathrm{C}(\mathrm{N}=848)$ and serum creatinine measurements $(\mathrm{N}=625)$, and reported their annual household income (final $\mathrm{N}=462$ ). Analyses of urinary albumin to creatinine ratio were restricted to participants who also underwent baseline urine assessments $(\mathrm{N}=301)$.

\section{HANDLS: measurements and definitions}

Demographic data, including age, sex, race, employment, educational and insurance status, and annual household income were obtained during an initial household survey by self-report. Poverty status was also determined at baseline and was based on reported annual household income below or above 125\% of the 2004 US Department of Health and Human Services poverty guideline [23].

A health care provider in a mobile research vehicle obtained participants' medical and social histories and performed physical examinations. Hypertension was defined as an average of seated and standing systolic blood pressure $\geq 140 \mathrm{~mm} \mathrm{Hg}$, an average of seated and standing diastolic blood pressure $\geq 90 \mathrm{~mm} \mathrm{Hg}$ [24], a history of blood pressure medication use, and/or a self-report of a history of hypertension. Cardiovascular disease was defined as a self-report of a history of congestive heart failure, enlarged heart, angina, chest pain, myocardial infarction, coronary artery disease, mini-stroke, or cerebrovascular accident. Height and weight were measured and used to calculate BMI to determine the presence of obesity, defined as $\mathrm{BMI} \geq 30$.

Fasting venous blood specimens and spot urine samples were also collected in the mobile research vehicle and analyzed at the NIA Clinical Research Branch Core Laboratory (Baltimore, MD, USA) and Quest Diagnostics Inc. (Baltimore, MD and Chantilly, VA, USA). Diabetes mellitus was defined as a fasting plasma glucose concentration of $\geq 126 \mathrm{mg} / \mathrm{dl}(7.0 \mathrm{mmol} / \mathrm{l})$, Hemoglobin A1c $\geq 6.5 \%$ or self-report of diabetes. Serum creatinine was measured at Quest Diagnostics Inc. by isotope dilution mass spectrometry (Olympus America Inc., Melville, NY, USA) and standardized to the reference laboratory at the Cleveland Clinic. Serum cystatin $\mathrm{C}$ assays were run in collaboration with the Department of Pathology at the University of Maryland on the Dimension Vista system from Siemens (Glasgow, DE) using the Flex ${ }^{\circ}$ reagent cartridge. The serum creatinine and cystatin $C$ were used to estimate GFR using the combined creatinine-cystatin $\mathrm{C}$ equation (eGFR) [25,26]. Urinary albumin to creatinine measures were performed at Quest Diagnostics Inc. using 
an immmunoturbidimetric assay (Kamiya Biomedical Co., Seattle, Wash. USA).

Percent European ancestry was estimated with STRUCTURE software that uses genotype data to assign individuals to a population of origin. We entered 2000 ancestry informative markers into our model to estimate the percent European ancestry of study participants [27].

\section{APOL1 Genotyping, imputation, and quality control}

A total of 1024 study participants were successfully genotyped using the Illumina $1 \mathrm{M}$ single-nucleotide polymorphism (SNP) genotyping array, passing inclusion criteria into the study. Initial inclusion criteria includes concordance between self-reported sex and sex estimated from X chromosome heterogeneity, > 95\% genotype call rate per participant, concordance between self-reported African ancestry and ancestry confirmed by analyses of genotyped SNPs, and no cryptic relatedness to any other samples at a level of proportional sharing of genotypes > 15\%. In addition, SNPs with Hardy-Weinberg equilibrium p-value $>1 \times 10^{-7}$, missing by haplotype p-value $>1 \times 10^{-7}$, minor allele frequency $>0.01$, and call rate $>95 \%$ were included. Quality control was conducted using PLINK 1.06 [28]. Genotypes that passed quality control criteria were used for genotype imputation. Imputation was performed using $\mathrm{MACH}$ and minimac software (http://www.sph. umich.edu/csg/abecasis/mach/) based on phase 1 alpha freeze version 3 data of the 1000 Genomes Project multiethnic panel. Imputed SNP dosages and best guess genotypes for rs73885319, rs60910145, and rs71785313 in APOL1 gene were extracted from the imputation dataset to generate G1 and G2 APOL1 risk haplotypes. Imputation quality indicated by $\mathrm{R}^{2}$ estimates in MACH for rs73885319, rs60910145, and rs71785313 were 0.84, 0.84, and 0.94, respectively. An $\mathrm{R}^{2}>0.30$ indicates good accuracy of genotype imputation. The linkage disequilibrium (LD) values between rs73885319 and rs60910145 were r2=1.0 and $\mathrm{D}^{\prime}=1.0$, indicating the SNPs were in perfect LD.

\section{Exposures of interest}

The two primary exposures we examined were APOL1 and annual household income. Given previous studies have shown the association between risk of kidney disease and APOL1 to follow a recessive mode of inheritance $[3,6,7,9]$, we treated $A P O L 1$ as a dichotomous variable with participants defined as low risk APOL1 (0 or 1 high risk variant) or high risk $A P O L 1$ ( 2 high risk variants).

We created quintiles of annual household income in order to better delineate differences in income, with 1 corresponding to the lowest quintile, because the majority of our cohort lived in poverty (72\%). For the purposes of analysis, we divided these quintiles into two groups. The first group included those who fell into income quintiles $<3$, which corresponded to an annual household income $<\$ 14,000 /$ year and from here on will be referred to as the 'lowest income group'. The second group included those who fell into income quintiles $\geq 3$, which corresponded to an annual household income $\geq \$ 14,000 /$ year, here on referred to as the 'higher income group'.

\section{Outcome measures}

The primary outcomes of our study were 1) mildly reduced eGFR, defined as eGFRcys $<75 \mathrm{~mL} / \mathrm{min} / 1.73 \mathrm{~m}^{2}$, as this threshold is associated with higher risk of ESRD, death and cardiovascular disease ${ }^{2}$ [25], and 2) high urinary albumin to creatinine ratio (ACR), defined as ACR $\geq$ $17 \mathrm{mg} / \mathrm{g}$ in men and $\geq 25 \mathrm{mg} / \mathrm{g}$ in women [29]. We also performed additional analyses of significantly reduced eGFR (<60 mL/min/1.73 $\left.\mathrm{m}^{2}\right)$ and high ACR ( $\left.\geq 30 \mathrm{mg} / \mathrm{g}\right)$.

\section{Statistical analyses}

We examined participant characteristics stratified by APOL1 status and then by income status. To evaluate for any significant differences in these characteristics, $t$ tests were used for continuous variables, and Fisher's exact tests were used for categorical variables.

We used multivariable logistic regression models to determine the relationship of APOL1 and income with our outcomes. We created separate models for the association of APOL1 with the outcome of interest and the association of income with the outcome of interest. Next, we created a combined model that included both APOL1 and income as exposures, and then determined the association of each individual exposure with the outcome of interest. This combined model was then adjusted for age, sex, and \% European ancestry. The unadjusted and adjusted models were tested for potential effect modification using interaction terms for $A P O L 1 \times$ income. We also assessed the variance in early kidney damage explained by $A P O L 1$ risk variants and income status by quantifying the difference in Nagelkerke's $R^{2}$ value from the adjusted logistic regression model (which included age, sex and \% European ancestry) with and without the inclusion of $A P O L 1$ or income.

\section{Sensitivity analyses}

To assess whether our results varied by choice of primary measure of SES, we conducted several sensitivity analyses. We analyzed our primary outcomes (eGFR < 75 and albuminuria) substituting income, separately, with education level (dichotomized by high school diploma or equivalency), employment status (based on employment in the past month), health insurance coverage (yes versus no), and regular source of health care (yes versus no). 


\section{Results}

\section{Participant characteristics}

A total of 462 HANDLS participants were included in our sample. Those that were not included were of similar age and sex as those included, however, poverty was much less prevalent among those not included $(40 \%)$ as compared to those included (72\%) in our analysis. Also, notably, a total of $16 \%$ of participants in our sample had high risk APOL1 status, compared to $8 \%$ in the full sample $(\mathrm{n}=1024)$ of African American HANDLS participants who underwent genotyping. The mean age of participants was 47.4 (SD 8.9) years and 57.4\% were female (Table 1).

When stratified by APOL1 status, there were no significant differences in socio-demographic, clinical (hypertension, systolic blood pressure, diabetes, cardiovascular disease or total cholesterol) or behavioral factors. The median income in this sample fell between $\$ 17,500$ and $\$ 20,000$, and the majority of participants lived in poverty. When stratified by income above or below $\$ 14,000$, those in the lowest income group were more likely to be unemployed and more likely to have smoked cigarettes than the higher income participants $(\mathrm{P}<0.05$ for both). Also, while non-significant, hypertension was more prevalent among the lowest income group. The higher income group had higher total cholesterol and obesity prevalence than the lowest income participants ( $\mathrm{P}<0.05$ for both).

\section{Analyses of reduced eGFR}

The mean eGFR of the sample was $99 \mathrm{~mL} / \mathrm{min} / 1.73 \mathrm{~m}^{2}$. Estimated GFR in the high-risk group was lower than in the low-risk APOL1 group, but the difference was not statistically significant [96 (SD 23) versus 100 (SD 20); P = $0.2]$. The overall prevalence of eGFR $<75 \mathrm{~mL} / \mathrm{min} / 1.73 \mathrm{~m}^{2}$ was $11 \%(\mathrm{n}=51)$. Compared with persons with low-risk APOL1, high-risk persons were at $50 \%$ higher odds of eGFR $<75$, but estimates did not reach statistical significance (Table 2). There was a significantly greater odds of reduced eGFR in the lowest income group compared to the higher income group that was consistent in unadjusted and adjusted models [adjusted odds ratio (aOR) 1.81, 95\% Confidence Interval (CI) 1.21, 2.72; $\mathrm{p}=0.004$ ]. There was no evidence of effect modification. Fully, $53 \%$ of participants with eGFR $<75$ were among the lowest income group while only $22 \%$ were in the high risk APOL1 group. The variance in eGFR $<75$ explained by the inclusion of APOL1 in our model adjusted for age, sex and \% European ancestry was $0.4 \%$ compared to $1.5 \%$ explained by the inclusion of income.

Estimated GFR $<60 \mathrm{ml} / \mathrm{min} / 1.73 \mathrm{~m}^{2}$ was prevalent among $4.1 \%$ of participants, and high-risk APOL1 status was strongly associated with this outcome (aOR 2.48, 95\% CI 2.29- 2.68; $\mathrm{p}=<0.001)$ while the lowest income group was not $(\mathrm{aOR} 1.06,95 \% \mathrm{CI} 0.31-3.65 ; \mathrm{p}=0.92)$,

Table 1 Participant characteristics by APOL1 Risk group and income

\begin{tabular}{|c|c|c|c|c|c|c|c|}
\hline \multirow[b]{2}{*}{ Characteristic } & \multirow[b]{2}{*}{$\mathbf{n}$} & \multicolumn{3}{|c|}{ APOL1 Risk group } & \multicolumn{3}{|l|}{ Income status } \\
\hline & & $\begin{array}{l}\text { Low-Risk } \\
(\mathrm{n}=389)\end{array}$ & $\begin{array}{l}\text { High-Risk } \\
(n=73)\end{array}$ & $\begin{array}{l}P \\
\text { value }\end{array}$ & $\begin{array}{l}\text { Lowest Income }<14,000 / y r) \\
(n=185)\end{array}$ & $\begin{array}{l}\text { Higher Income }(\geq 14,000 / y r \\
(n=277)\end{array}$ & $\begin{array}{l}P \\
\text { value }\end{array}$ \\
\hline \multicolumn{8}{|l|}{ Demographics } \\
\hline Age $(S D)$, years & 462 & $47.6(8.9)$ & $45.9(9.0)$ & 0.123 & $47.9(8.9)$ & $47.0(8.9)$ & 0.253 \\
\hline Female, \% & 462 & 56.3 & 63.0 & 0.305 & 58.9 & 56.3 & 0.631 \\
\hline $\begin{array}{l}\text { Percentage European Ancestry (SD), } \\
\%\end{array}$ & 462 & $17.4(8.5)$ & $16.7(8.7)$ & 0.570 & $17.9(9.3)$ & $16.8(8.0)$ & 0.161 \\
\hline \multicolumn{8}{|l|}{ Socioeconomic Factors } \\
\hline Less than high school education, $\%$ & 462 & 33.9 & 30.1 & 0.590 & 30.8 & 35.0 & 0.366 \\
\hline Unemployed, \% & 411 & 40.9 & 39.3 & 0.888 & 66.3 & 23.3 & $<0.001$ \\
\hline Uninsured, \% & 411 & 38.3 & 30.1 & 0.234 & 42.2 & 33.6 & 0.063 \\
\hline No regular health care source, \% & 411 & 37.7 & 36.1 & 0.886 & 45.8 & 31.8 & 0.005 \\
\hline \multicolumn{8}{|l|}{ Clinical and Behavioral Factors } \\
\hline Hypertension, \% & 429 & 55.7 & 50.0 & 0.427 & 60.0 & 51.4 & 0.092 \\
\hline $\begin{array}{l}\text { Systolic Blood Pressure, mean (SD), } \\
\mathrm{mmHg}\end{array}$ & 450 & $123(18)$ & $121(16)$ & 0.534 & $122(19)$ & $122(18)$ & 0.891 \\
\hline Diabetes, $\%$ & 462 & 24.9 & 19.2 & 0.370 & 20.5 & 26.4 & 0.182 \\
\hline Cardiovascular Disease, \% & 461 & 17.8 & 19.2 & 0.742 & 21.1 & 15.9 & 0.175 \\
\hline $\begin{array}{l}\text { Total Serum Cholesterol, mean (SD), } \\
\mathrm{mg} / \mathrm{dL}\end{array}$ & 462 & $184(48)$ & $191(43)$ & 0.257 & $178(42)$ & $190(51)$ & 0.007 \\
\hline Obesity, \% & 457 & 41.3 & 38.9 & 0.794 & 34.4 & 45.3 & 0.025 \\
\hline Tobacco Use $\geq 100$ cigs, $\%$ & 435 & 70.5 & 69.6 & 0.886 & 76.8 & 66.3 & 0.023 \\
\hline
\end{tabular}


Table 2 Odds of eGFR $<75$ or $<60 \mathrm{ml} / \mathrm{min} / 1.73 \mathrm{~m}^{2}$ by APOL1 risk group and income category, $\mathrm{N}=462$

\begin{tabular}{|c|c|c|c|c|c|c|}
\hline \multirow[t]{2}{*}{ Model - Variables } & \multicolumn{2}{|c|}{$\begin{array}{l}\text { Odds Ratios for eGFR }<75 \text { (95\% } \\
\text { Confidence Interval) } n=51 \text { events }\end{array}$} & \multirow{2}{*}{$\begin{array}{l}\mathrm{P} \text { interaction } \\
\text { (APOL1 } \mathrm{x} \\
\text { Income) }\end{array}$} & \multicolumn{2}{|c|}{$\begin{array}{l}\text { Odds Ratios for eGFR }<60 \text { (95\% } \\
\text { Confidence Interval) } n=19 \text { events }\end{array}$} & \multirow{2}{*}{$\begin{array}{l}\text { P interaction } \\
\text { (APOL1 x } \\
\text { Income) }\end{array}$} \\
\hline & $\begin{array}{l}\text { High-risk versus } \\
\text { Low-risk } A P O L 1 \\
\text { variants }\end{array}$ & $\begin{array}{l}\text { Lowest Income } \\
\text { versus Higher } \\
\text { Income Groups }\end{array}$ & & $\begin{array}{l}\text { High-risk versus } \\
\text { Low-risk } A P O L 1 \\
\text { variants }\end{array}$ & $\begin{array}{l}\text { Lowest Income } \\
\text { versus Higher } \\
\text { Income Groups }\end{array}$ & \\
\hline \multicolumn{7}{|l|}{$\begin{array}{l}\text { Individual } \\
\text { Variables }\end{array}$} \\
\hline APOL1 & $1.55(0.91,2.63)$ & - - & & $2.59(2.48,2.70)$ & -—- & \\
\hline Income & -— & $1.80(1.22,2.67)$ & & -—- & $1.09(0.35,3.41)$ & \\
\hline \multicolumn{7}{|l|}{ Additive Models } \\
\hline $\begin{array}{l}\text { APOL1, Income } \\
\text { Category }\end{array}$ & $1.54(0.91,2.61)$ & $1.80(1.23,2.63)$ & 0.903 & $2.59(2.47,2.71)$ & $1.08(0.36,3.22)$ & 0.06 \\
\hline $\begin{array}{l}\text { + Age, Sex, } \\
\text { Percent European } \\
\text { ancestry }\end{array}$ & $1.50(0.90,2.49)$ & $1.81(1.21,2.72)$ & 0.653 & $2.48(2.29,2.68)$ & $1.06(0.33,3.36)$ & 0.09 \\
\hline
\end{tabular}

when compared to the low-risk $A P O L 1$ and higher income groups, respectively. The variance in eGFR $<60$ explained by the inclusion of APOL1 in our adjusted model was $2.1 \%$ compared to $0.1 \%$ explained by the inclusion of income. There was some evidence of effect modification ( $p$ interaction 0.09 for APOL1 $\times$ income in our adjusted model) (Table 3). In unadjusted (due to the low event rate) models stratified by income group, high-risk APOL1 was associated with greater odds of eGFR $<60$ only in the lowest income group (OR 5.81, 95\% 2.32-14.55). There was no statistically significant association with APOL1 in the higher income group (OR 1.22, 95\% 0.59-2.53).

\section{Analyses of elevated urinary albumin-to-creatinine}

Among the 301 participants who provided a urine sample, the median urinary ACR was $0.8 \mathrm{mg} / \mathrm{g}$ [interquartile range (IQR) $0.50-2.60]$. A total of $7.0 \%$ of participants had elevated ACR (defined by sex-specific cut points). High-risk APOL1 status was strongly associated with greater odds of elevated ACR (aOR 3.76, 95\% CI 1.95, 7.25); and there was a non-significant association of lower income and elevated ACR, with no evidence of effect modification (Table 4).

Among persons with elevated ACR, 29\% were in the high-risk APOL1 group and 33\% were in the lowest income group); and the majority had hypertension (85\%) and/or diabetes (57\%). The variance in elevated ACR explained by the inclusion of APOL1 in our adjusted model was $5.7 \%$ compared to $1.5 \%$ explained by the inclusion of income. Subsequent inclusion of hypertension and diabetes to our primary model, separately, explained $8.9 \%$ and $7.5 \%$, respectively, of the variance in elevated ACR.

A total of 11 (3.7\%) participants had high ACR ( $\geq 30 \mathrm{mg} /$ g). In unadjusted models (due to a low event rate), highrisk $A P O L 1$ status was associated with high ACR, however estimates were not statistically significant (OR 3.19, 95\% CI 0.55-18.59). Income was not associated with high ACR (OR 0.90, 95\% CI 0.48-1.72).

\section{Sensitivity analyses}

Our analyses substituting income for other measures of SES yielded results which were qualitatively similar to our primary analyses, except in the case of our inclusion

Table 3 Association of APOL1 and income with sex-specific elevated albumin-to-creatinine ratio $(A C R), N=301$

\begin{tabular}{|c|c|c|c|}
\hline \multirow[t]{2}{*}{ Model - Variables } & \multicolumn{2}{|c|}{ Odds Ratios for Elevated ACR ( $95 \%$ Confidence Interval) $n=21$ events } & \multirow{2}{*}{$\begin{array}{l}\text { P interaction } \\
\text { (APOL1 } \mathrm{x} \text { Income) }\end{array}$} \\
\hline & $\begin{array}{l}\text { High-risk versus Low-risk APOL1 } \\
\text { variants }\end{array}$ & $\begin{array}{l}\text { Lowest Income versus Higher Income } \\
\text { Groups }\end{array}$ & \\
\hline \multicolumn{4}{|l|}{ Individual Variables } \\
\hline APOL1 & $3.69(2.01,6.78)$ & -—— & \\
\hline Income & -—— & $1.91(0.72,5.08)$ & \\
\hline \multicolumn{4}{|l|}{ Additive Models } \\
\hline APOL1, Income Category & $3.56(2.06,6.16)$ & $1.79(0.68,4.74)$ & 0.811 \\
\hline $\begin{array}{l}\text { + Age, Sex, Percent European } \\
\text { ancestry }\end{array}$ & $3.76(1.95,7.25)$ & $1.78(0.70,4.49)$ & 0.727 \\
\hline
\end{tabular}


Table 4 Sensitivity analysis

\begin{tabular}{|c|c|c|c|c|c|c|}
\hline \multirow[t]{2}{*}{ Model - Variables } & \multicolumn{2}{|c|}{$\begin{array}{l}\text { Odds Ratios for eGFR }<75 \\
\text { ( } 95 \% \text { Confidence Interval) } \\
n=51 \text { events }\end{array}$} & \multirow[t]{2}{*}{$\begin{array}{l}\text { P interaction } \\
\text { (APOL1 x SES } \\
\text { measure) }\end{array}$} & \multicolumn{2}{|c|}{$\begin{array}{l}\text { Odds Ratios for Elevated ACR } \\
\text { (95\% Confidence Interval) } \\
n=21 \text { events }\end{array}$} & \multirow[t]{2}{*}{$\begin{array}{l}\text { P interaction } \\
\text { (APOL1 } \times \text { SES } \\
\text { measure) }\end{array}$} \\
\hline & $\begin{array}{l}\text { High-risk versus } \\
\text { Low-risk } A P O L 1 \\
\text { variants }\end{array}$ & $\begin{array}{l}\text { Low SES versus } \\
\text { Higher SES } \\
\text { Group }\end{array}$ & & $\begin{array}{l}\text { High-risk versus } \\
\text { Low-risk } A P O L 1 \\
\text { variants }\end{array}$ & $\begin{array}{l}\text { Low SES versus } \\
\text { Higher SES } \\
\text { Group }\end{array}$ & \\
\hline \multicolumn{7}{|l|}{ Additive Models } \\
\hline APOL 1, Education & $1.60(1.00,2.57)$ & $1.95(1.50,2.54)$ & 0.4 & $3.89(2.28,6.63)$ & $1.68(0.34,8.23)$ & 0.823 \\
\hline $\begin{array}{l}\text { APOL1, } \\
\text { Employment }\end{array}$ & $2.06(1.53,2.78)$ & $4.64(3.40,6.33)$ & $0.017^{*}$ & $3.12(1.73,5.63)$ & $1.32(0.83,2.08)$ & 0.894 \\
\hline $\begin{array}{l}\text { APOL } 1 \text {, Health } \\
\text { Insurance }\end{array}$ & $1.92(1.27,2.90)$ & $1.00(0.53,1.89)$ & 0.662 & $3.04(1.65,5.60)$ & $0.56(0.14,2.28)$ & $\begin{array}{l}{ }^{*} \text { could not be } \\
\text { determined }\end{array}$ \\
\hline $\begin{array}{l}\text { APOL1, Regular } \\
\text { Health Care } \\
\text { Source }\end{array}$ & $1.91(1.15,3.17)$ & $0.54(0.31,0.94)$ & 0.871 & $3.09(1.56,6.13)$ & $0.64(0.14,2.86)$ & $\begin{array}{l}{ }^{* *} \text { could not be } \\
\text { determined }\end{array}$ \\
\hline
\end{tabular}

of health insurance and a regular source of health care (Table 4). For these metrics of access to care, only highrisk APOL1 was associated with greater odds of mildly reduced eGFR or elevated ACR. There was some evidence of effect modification noted, with high-risk $A P O L 1$ only being associated with greater odds of eGFR $<75$ among unemployed participants ( $\mathrm{p}$ interaction $=0.017$ for $A P O L 1 \times$ employment status).

\section{Discussion}

In this study, we evaluated a cohort of young African Americans largely free of established CKD to examine the relation of $A P O L 1$, income and early kidney disease. We found that income, but not high-risk APOL1, was significantly associated with mildly reduced kidney function. Upon examining further reductions in kidney function $($ eGFR $<60)$, the association of high-risk APOL1 and reduced kidney function was significant. We also found that high-risk $A P O L 1$ status, but not income, was significantly associated with elevated ACR. The associations of APOL1 with markers of early kidney disease did not vary by income category, or vice versa.

Few other studies have examined the association of APOL1 with milder forms of kidney disease and findings have varied. Foster, et al. [10] performed a prospective study examining a cohort of African Americans with no CKD at baseline and found an increased risk for eGFR < 60 and progression to ESRD among those with the highrisk genotype. Friedman, et al. [8] found a 3-fold increased risk of eGFR $<60$ and microalbuminuria associated with high risk APOL1 among nondiabetic African Americans in a cross-sectional study; however, this association did not persist among persons with diabetes.
Freedman, et al. [9] examined these cross-sectional relationships in relatives of patients with non-diabetic ESRD. They found a significant association between APOL1 and macroalbuminuria, but not with microalbuminuria or eGFR $<60$. In aggregate, these studies and ours suggest that high-risk $A P O L 1$ variants may be more strongly associated with advanced and progressive kidney disease than with early disease, arguing for a primary role of APOL1 as a progression rather than initiation factor in CKD.

Recent advances have swung the pendulum of research and clinical thought regarding the etiology of racial disparities in kidney disease towards the role of genetic contributions. The results of our study suggest that genetic factors may not fully explain these disparities. In this sample largely free of CKD, a large proportion of individuals with early kidney damage were among those without high-risk APOL1 variants. Rather, diabetes and/ or hypertension were prevalent among the majority of participants with early kidney damage. Thus, despite the highly significant association between high-risk APOL1 and kidney disease among African Americans in multiple recent studies $[3,4,7,10]$, it may not be the only contributor to early kidney disease in this population. Other factor(s), including those related to and influenced by SES, may be the primary initiators of CKD among African Americans. In our study, for example, we found that only about a third of individuals with elevated ACR had high-risk $A P O L 1$ variants, however, the overwhelming majority had hypertension. Therefore, early CKD identification and treatment of modifiable risk factors, such as hypertension, may offer the greatest opportunity for reducing CKD disparities among minority and low income populations. 
Our finding of greater odds of eGFR $<75$ among the lowest compared to the higher income group is consistent with prior studies implicating SES as a major predictor of early kidney disease among African Americans [12,13]. Our analyses of other indicators of SES were generally consistent with the income analyses, except our finding of no association between access to care measures and eGFR $<75$. Here, reverse causality was possible, as individuals in poor health (ie. with reduced kidney function and other chronic illnesses) may be more able to obtain public health insurance and may seek care more often than healthier persons. There are multiple possible mechanisms through which low SES could lead to increased risk of kidney disease, most of which have yet to be thoroughly investigated. Aside from its potential impact on receipt of high quality health care, there are less obvious mechanisms, related to the social environment and psychosocial impact of low SES that may contribute as well [30,31]. Future studies are warranted elucidating pathways between low SES and kidney disease.

The limitations of our study should be considered. First, its cross-sectional design disallows direct causal inferences regarding the associations examined, and thus, longitudinal studies of this kind are needed. Second, despite our stratifying participants around an annual income of $\$ 14,000$, our study population was largely comprised of low income individuals, which may have influenced our results. Third, we lacked complete data on some variables included in our sensitivity analyses. Finally, our relatively low event rate for early kidney damage did not allow adjustment for multiple covariates, or more granular analyses of income levels; and unmeasured confounders, particularly of the association of income and early kidney disease, are likely. Our power to detect statistically significant differences was limited in some of our models (Additional file 1). We included adjustment for a parsimonious set of variables despite the low event rate, and found that this did not substantially alter the point estimates of our univariate models. While our findings can serve to generate hypotheses, larger studies more representative of all African Americans are warranted addressing these relationships among wellcharacterized populations with a greater range of kidney disease.

\section{Conclusions}

Our study is one of few examining the association of both genetic and environmental factors with early kidney damage [32]. In a population of urban-dwelling, primarily low-income African Americans, we found that genetic factors were significantly associated with albuminuria and significantly reduced eGFR, however, income level was a correlate of less severe markers of early kidney damage. Thorough examination of the burden of CKD among African Americans may require consideration of both genetic as well as environmental factors.

\section{Additional file}

Additional file 1: Power calculations for unadjusted models.

Competing interests

The authors declare that they have no competing interests.

\section{Authors' contributions}

DC and CP conceived of the study design. DC and ST analyzed and interpreted the data. RT, DC and ST drafted the manuscript. CP interpreted the data and revised the manuscript. $M E$ and $A Z$ directed the collection of the data analyzed in the study and revised the manuscript. All authors read and approved the final manuscript.

\section{Acknowledgements}

This work was supported by the Intramural Research Program of the National Institute on Aging, National Institutes of Health (NIH). Dr. Crews was supported by the Harold Amos Medical Faculty Development Program of the Robert Wood Johnson Foundation, grant K23DK097184 from the National Institute of Diabetes and Digestive and Kidney Diseases (NIDDK), NIH, and the Gilbert S. Omenn Anniversary Fellowship of the Institute of Medicine.

\section{Author details}

'Department of Medicine, Johns Hopkins University School of Medicine, Baltimore, MD, USA. ${ }^{2}$ Department of Medicine, University of California, San Francisco, CA, USA. ${ }^{3}$ San Francisco VA Medical Center, San Francisco, CA, USA. ${ }^{4}$ Laboratory of Epidemiology and Population Sciences, National Institute on Aging, National Institutes of Health, Baltimore, MD, USA. ${ }^{5}$ Welch Center for Prevention, Epidemiology and Clinical Research, Johns Hopkins Medical Institutions, Baltimore, MD, USA. ${ }^{6}$ Center on Aging and Health, Johns Hopkins Medical Institutions, Baltimore, MD, USA. ${ }^{7}$ Division of Nephrology, Johns Hopkins University School of Medicine, Johns Hopkins Bayview Medical Center, 301 Mason F. Lord Drive, Suite 2500, Baltimore, MD 21224, USA.

Received: 20 August 2014 Accepted: 27 January 2015

Published online: 10 February 2015

\section{References}

1. Fornoni A, Merscher S, Kopp JB. Lipid biology of the podocyte-new perspectives offer new opportunities. Nat Rev Nephrol. 2014;10(7):379-88.

2. Vanhollebeke B, Pays E. The function of apolipoproteins L. Cell Mol Life Sci. 2006;63(17):1937-44.

3. Genovese G, Friedman DJ, Ross MD, Lecordier L, Uzureau P, Freedman BI, et al. Association of trypanolytic ApoL1 variants with kidney disease in African Americans. Science (New York, NY). 2010;329(5993):841-5.

4. Freedman BI, Divers J, Palmer ND. Population ancestry and genetic risk for diabetes and kidney, cardiovascular, and bone disease: modifiable environmental factors may produce the cures. Am J Kidney Dis. 2013;62 (6):1165-75.

5. Lipkowitz MS, Freedman BI, Langefeld CD, Comeau ME, Bowden DW, Kao WH, et al. Apolipoprotein L1 gene variants associate with hypertension-attributed nephropathy and the rate of kidney function decline in African Americans. Kidney Int. 2013;83(1):114-20.

6. Kopp JB, Nelson GW, Sampath K, Johnson RC, Genovese G, An P, et al. APOL1 genetic variants in focal segmental glomerulosclerosis and HIV-associated nephropathy. J Am Soc Nephrol. 2011;22(11):2129-37.

7. Parsa A, Kao WH, Xie D, Astor BC, Li M, Hsu CY, et al. APOL1 risk variants, race, and progression of chronic kidney disease. N Engl J Med. 2013;369 (23):2183-96.

8. Friedman DJ, Kozlitina J, Genovese G, Jog P, Pollak MR. Population-based risk assessment of APOL1 on renal disease. J Am Soc Nephrol. 2011;22 (11):2098-105

9. Freedman BI, Langefeld CD, Turner J, Nunez M, High KP, Spainhour M, et al. Association of APOL1 variants with mild kidney disease in the first-degree relatives of African American patients with non-diabetic end-stage renal disease. Kidney Int. 2012:82(7):805-11.

10. Foster MC, Coresh J, Fornage M, Astor BC, Grams M, Franceschini N, et al. APOL1 variants associate with increased risk of CKD among African Americans. J Am Soc Nephrol. 2013;24(9):1484-91. 
11. Crews DC, Pfaff T, Powe NR. Socioeconomic factors and racial disparities in kidney disease outcomes. Semin Nephrol. 2013;33(5):468-75.

12. Bruce MA, Beech BM, Crook ED, Sims M, Wyatt SB, Flessner MF, et al. Association of socioeconomic status and CKD among African Americans: the Jackson Heart Study. Am J Kidney Dis. 2010;55(6):1001-8.

13. Crews DC, Charles RF, Evans MK, Zonderman AB, Powe NR. Poverty, race, and $C K D$ in a racially and socioeconomically diverse urban population. Am J Kidney Dis. 2010;55(6):992-1000.

14. Crews DC, McClellan WM, Shoham DA, Gao L, Warnock DG, Judd S, et al. Low income and albuminuria among REGARDS (Reasons for Geographic and Racial Differences in Stroke) study participants. Am J Kidney Dis. 2012;60(5):779-86.

15. Volkova N, McClellan W, Klein M, Flanders D, Kleinbaum D, Soucie JM, et al Neighborhood poverty and racial differences in ESRD incidence. J Am Soc Nephrol. 2008;19(2):356-64

16. Norris K, Nissenson AR. Race, gender, and socioeconomic disparities in CKD in the United States. J Am Soc Nephrol. 2008;19(7):1261-70.

17. Franco M, Diez-Roux AV, Nettleton JA, Lazo M, Brancati F, Caballero B, et al Availability of healthy foods and dietary patterns: the Multi-Ethnic Study of Atherosclerosis. Am J Clin Nutr. 2009:89(3):897-904.

18. Johnson AE, Boulware LE, Anderson CA, Chit-Ua-Aree T, Kahan K, Boyer LL, et al. Perceived barriers and facilitators of using dietary modification for CKD prevention among African Americans of low socioeconomic status: a qualitative study. BMC Nephrol. 2014;15(1):194.

19. Crews DC, Kuczmarski MF, Miller ER, 3rd, Zonderman AB, Evans MK, Powe NR: Dietary Habits, Poverty, and Chronic Kidney Disease in an Urban Population. Journal of renal nutrition: the official journal of the Council on Renal Nutrition of the National Kidney Foundation 2014

20. Banerjee T, Crews DC, Wesson DE, Tilea A, Saran R, Rios Burrows N, et al. Dietary acid load and chronic kidney disease among adults in the United States. BMC Nephrol. 2014;15:137.

21. Lin J, Fung TT, Hu FB, Curhan GC. Association of dietary patterns with albuminuria and kidney function decline in older white women: a subgroup analysis from the Nurses' Health Study. Am J Kidney Dis. 2011;57(2):245-54.

22. Evans MK, Lepkowski JM, Powe NR, LaVeist T, Kuczmarski MF, Zonderman $A B$. Healthy aging in neighborhoods of diversity across the life span (HANDLS): overcoming barriers to implementing a longitudinal, epidemiologic, urban study of health, race, and socioeconomic status. Ethn Dis. 2010;20(3):267-75.

23. Health and Human Services Poverty Guidelines. U.S. Department of Health and Human Services, 2014. 2004 Health and Human Services Poverty Guidelines. http://aspe.hhs.gov/poverty/04fedreg.pdf (accessed February 10, 2014).

24. Chobanian AV, Bakris GL, Black HR, Cushman WC, Green LA, Izzo Jr JL, et al Seventh report of the Joint National Committee on Prevention, Detection, Evaluation, and Treatment of High Blood Pressure. Hypertension. 2003;42(6):1206-52.

25. Shlipak MG, Matsushita K, Arnlov J, Inker LA, Katz R, Polkinghorne KR, et al. Cystatin $C$ versus creatinine in determining risk based on kidney function. N Engl J Med. 2013;369(10):932-43.

26. Inker LA, Schmid $\mathrm{CH}$, Tighiouart $\mathrm{H}$, Eckfeldt JH, Feldman $\mathrm{HI}$, Greene $\mathrm{T}$, et al. Estimating glomerular filtration rate from serum creatinine and cystatin $\mathrm{C}$. N Engl J Med. 2012;367(1):20-9.

27. Pritchard JK, Stephens M, Donnelly P. Inference of population structure using multilocus genotype data. Genetics. 2000;155(2):945-59.

28. Purcell S, Neale B, Todd-Brown K, Thomas L, Ferreira MA, Bender D, et al. PLINK: a tool set for whole-genome association and population-based linkage analyses. Am J Hum Genet. 2007:81(3):559-75.

29. Warram JH, Gearin G, Laffel L, Krolewski AS. Effect of duration of type I diabetes on the prevalence of stages of diabetic nephropathy defined by urinary albumin/creatinine ratio. J Am Soc Nephrol. 1996;7(6):930-7.

30. Bruce MA, Beech BM, Sims M, Brown TN, Wyatt SB, Taylor HA, et al. Social environmental stressors, psychological factors, and kidney disease. J Investig Med. 2009;57(4):583-9.

31. Sims M, Diez-Roux AV, Dudley A, Gebreab S, Wyatt SB, Bruce MA, et al. Perceived discrimination and hypertension among African Americans in the Jackson Heart Study. Am J Public Health. 2012;102 Suppl 2:S258-65.

32. Peralta CA, Risch N, Lin F, Shlipak MG, Reiner A, Ziv E, et al. The Association of African Ancestry and elevated creatinine in the Coronary Artery Risk Development in Young Adults (CARDIA) Study. Am J Nephrol. 2010;31 (3):202-8

\section{Submit your next manuscript to BioMed Central and take full advantage of:}

- Convenient online submission

- Thorough peer review

- No space constraints or color figure charges

- Immediate publication on acceptance

- Inclusion in PubMed, CAS, Scopus and Google Scholar

- Research which is freely available for redistribution 